\title{
Non-vertical cave and dilution modelling at New Gold's New Afton Mine
}

\author{
J Parsons New Gold Inc., Canada \\ D Hamilton New Gold Inc., Canada \\ C Ludwicki Dassault Systèmes, Canada
}

\begin{abstract}
New Gold's New Afton Mine currently operates two separate caves: the West Cave and the East Cave. Both caves have seen external dilution and other symptoms of non-vertical cave growth towards the south. This non-vertical cave growth is believed to be caused by the weak picrite rock mass in the hanging wall. A geochemical analysis of the picrite unit identified marker elements that provided insight into the concept of non-vertical cave growth to the south; dilution pathways were identified, and the increase in picrite at certain locations across the footprint was incorporated into modelling the cave development.

Advanced modelling techniques using Dassault Systèmes' $P C B C^{T M}$ were employed to better model the complex flow behaviour. In the West Cave, the modelled draw cones were tilted to match the surface expression of the observed subsidence. In the East Cave, phantom drawpoints and forced cave backs were used to create a dilution model reflecting the picrite geochemical data. Both non-vertical PCBC cave models show improved reconciliations compared to the standard vertical mixing models.

This paper outlines the methodology used in modelling the complex flow behaviour experienced at New Afton Mine, and the improved grade reconciliation between the standard vertical mixing model and a non-vertical mixing model.
\end{abstract}

Keywords: New Afton, block caving, PCBC, modelling, non-vertical cave, dilution

\section{$1 \quad$ Introduction}

New Afton Mine is a 14,400 tpd block caving operation located $8 \mathrm{~km}$ west of the city of Kamloops, British Columbia. The mine has a reserve of approximately 55 million tonnes, with 1.1 million ounces of gold and 940 million pounds of copper. New Afton Mine is constructed below the historic Afton open pit mine, operated by Teck Corporation from 1977 until 1997. New Gold Inc. began construction and development of the New Afton Mine in 2007, and reached commercial production in August 2013, after having blasted its first undercut in June 2011 and the first drawbell in September 2011.

New Afton Mine's Lift 1 production level is split into two caves: the West Cave and the East Cave. The initial plan was to mine through a 'low-grade' central pillar, but subsequent interpretation has shown the pillar to be waste (Figure 1). Lift 1 mining commenced with the West Cave moving from west to east. The East Cave commenced production in 2014 starting from the central pillar and moving to the east. The Lift 1 extraction level has six parallel drives named $B$ to $G$ from north to south. The $B$ and $G$ drives have drawpoints on one side, whereas the other drives have drawpoints on both sides. Figure 1 shows a plan view of the New Afton extraction level.

Early in their cave lives, both caves began exhibiting signs of non-vertical cave growth, mostly in the form of unexpected external dilution. This non-vertical cave growth is believed to be caused by the weak picrite rock mass in the hanging wall. This paper outlines the methodology used in modelling the complex flow behaviour experienced at New Afton Mine, and the improved cave reconciliation between the standard vertical mixing model and a non-vertical mixing model. 


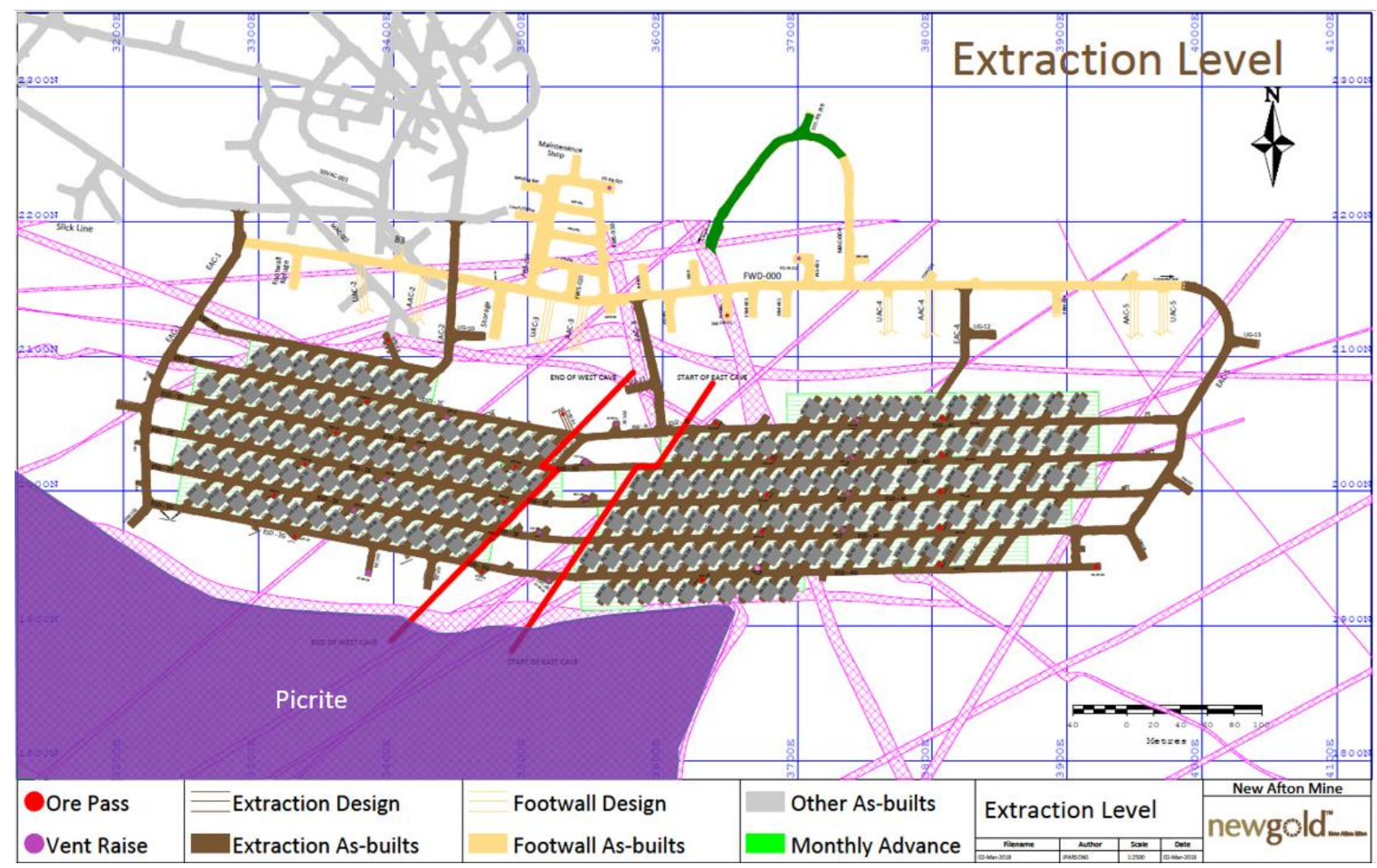

Figure 1 New Afton Mine extraction level plan view. Major faults in pink hashing. Picrite shown in purple

\subsection{Geologic setting}

New Afton is located in a belt of 200-205 Ma alkali porphyry Cu-Au-Ag deposits situated in the Quesnel volcanic arc. The deposit is classified as an alkalic porphyry copper-gold deposit related to the intrusion of a narrow monzonite stock that is associated with the Cherry Creek monzonite phase of the Iron Mask batholith. Mineralisation occurs as discontinuous copper sulphide stringer veinlets and disseminations hosted in intermediate to mafic volcanic rocks belonging to the Triassic Nicola Formation immediately adjacent to monzonite intrusions (Lipske \& Wade 2014).

\subsubsection{Lithology}

The New Afton lithological model is comprised of six principal units: crystalline and polymictic fragmental volcanic rocks, and monomictic intrusive breccias (BXF), picrite (PI), diorite (DI), monzonite (MO), sedimentary rocks (SED) and major faults (FA) including the Hanging Wall Fault and Footwall Fault (Lipske \& Wade 2014).

The principal host rock comprises crystalline and polymictic fragmental volcanics belonging to the Triassic Nicola Formation and lesser monolithic intrusive breccias consolidated into one lithology informally referred to as BXF. On the eastern half of the deposit, BXF is intruded by a coeval diorite stock. A rheological discontinuity occurs through the central and western parts of the deposit between an ultramafic flow (picrite) and brittle volcanic rocks (BXF). An elongated monzonite stock and dyke swarm intrudes the BXF and is controlled by the Hanging Wall Fault and picrite along the southern margin of the deposit. The monzonite is generally weakly mineralised to unmineralised and is interpreted as the causative intrusive phase that is less susceptible to the introduction of sulphide mineralisation; its geometry is best described as a narrow elongated stock that remains open at depth and pinches down plunge to the west (Lipske \& Wade 2014). 


\subsubsection{Structure}

The earliest and most prominent structures are near-vertical east-trending faults referred to as the Footwall Fault (FW Fault) and Hanging Wall Fault (HW Fault). The structural corridor formed by the HW Fault and FW Fault likely controlled the emplacement of the monzonite, and created a narrow-space environment for the concentration of gold and copper mineralisation. The HW Fault, to the south, is defined by carbonate healed faults along the picrite/BXF contact; the fault zone includes blocks of BXF, picrite, diorite and monzonite, and forms the southern limit to mineralisation at the extraction level. Figure 2 shows the FW Fault to the north, the HW Fault to the south, and the J-Fault linking the two structures.

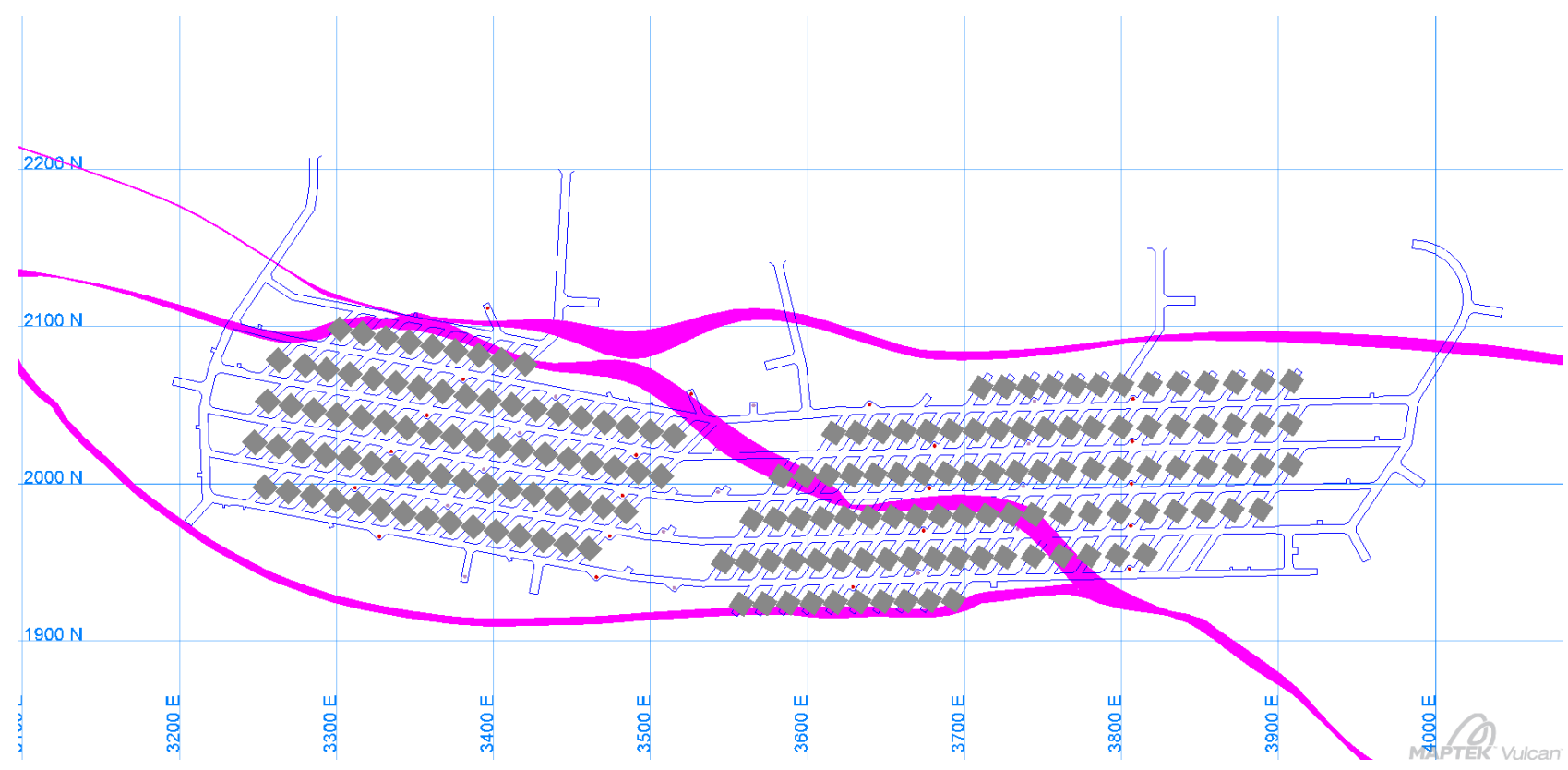

Figure 2 East-west trending FW and HW Faults

\section{Non-vertical cave growth and dilution}

\subsection{Subsidence}

New Afton subsidence monitoring programs began to show an acceleration in subsidence in early 2013 indicating that the West Cave had broken through to surface. As subsidence continued through 2013 and 2014, and further prism and drone flight data was collected, it showed that the centre of subsidence was not actually directly above the West Cave. As seen in Figure 3, the centre of subsidence was observed approximately $120 \mathrm{~m}$ to the southwest of the West Cave's centre; this location put the centre of subsidence directly above the weaker picrite unit, which was modelled to the south of the extraction footprint.

Given the apparent lean to the cave as seen in the surface expression, an influx of picrite dilution was expected along the southernmost drawpoints, and a need for a method to track, quantify and model this dilution was identified. 


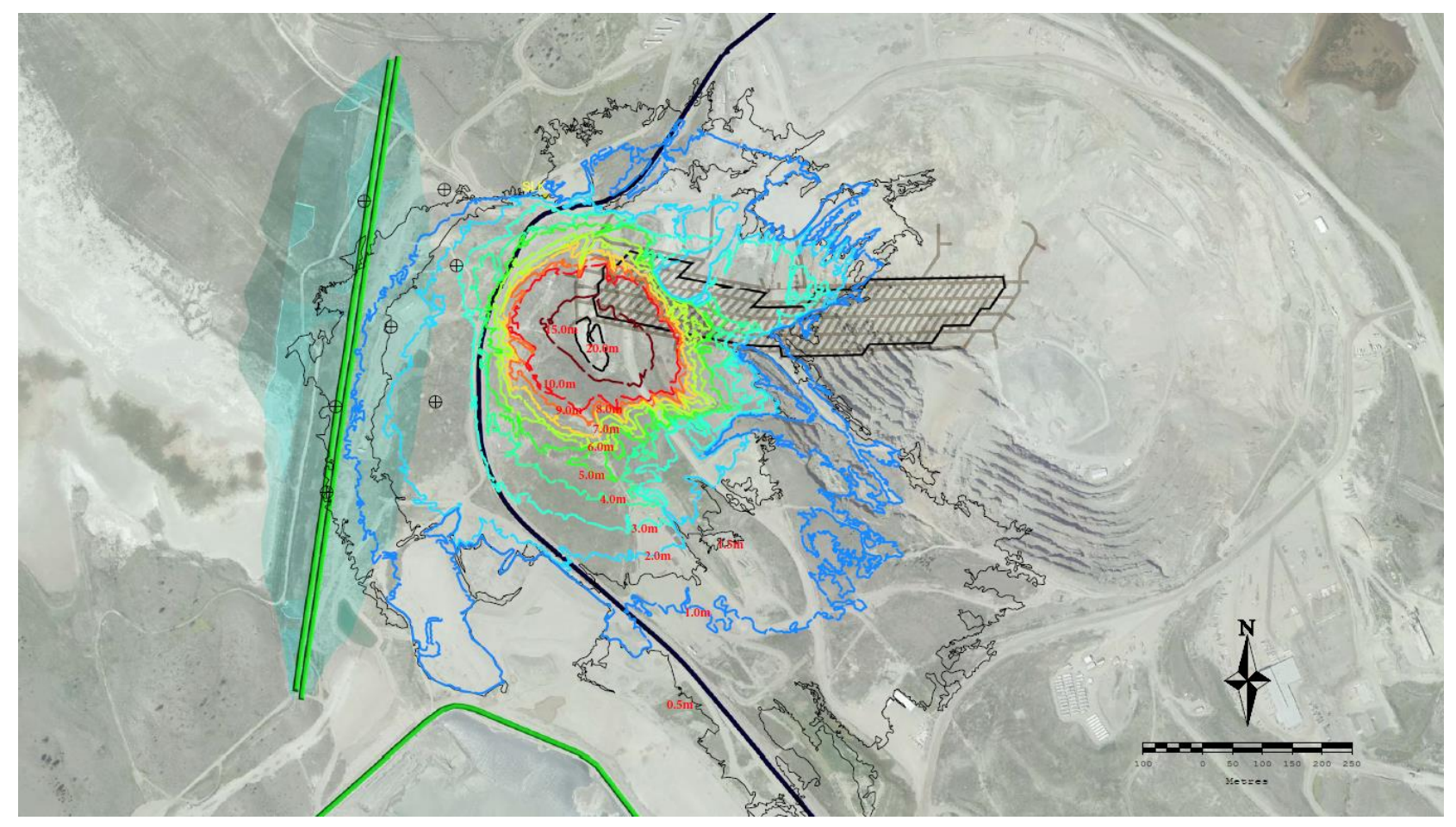

Figure 3 Surface subsidence contours overlayed on the production level footprint, showing measured centre of subsidence

\subsection{Datasets and geochemistry}

The New Afton exploration drillhole database provided 78,000 assayed samples with logs which provided the corresponding lithology. Table 1 shows the breakdown of the drillhole samples by lithology.

\section{Table 1 Exploration drillhole assays by lithology}

\begin{tabular}{ll}
\hline Lithology & Number of samples \\
\hline Picrite & 1,039 \\
HW Fault & 1,213 \\
Monzonite & 4,145 \\
Diorite & 6,981 \\
BXF & 64,775 \\
\hline
\end{tabular}

The exploration drillhole samples were assayed using a near total digest method, and 39 elements were reported for each interval. From the 39 elements reported from each interval, and when correlated with the associated lithology log, marker elements were identified for certain units (Table 2). Of the geochemistry marker elements identified, chromium and nickel values within the picrite unit were flagged as being four to 10 times those seen in other units. 
Table 2 Average ppm values for marker elements, by lithology

\begin{tabular}{llllllll}
\hline & Au (ppm) & Cu (ppm) & Ag (ppm) & As (ppm) & Hg (ppm) & Cr (ppm) & Ni (ppm) \\
\hline Picrite & 0.05 & 328.57 & 0.27 & 25.36 & 0.09 & 392.87 & 371.71 \\
Monzonite & 0.14 & $1,305.02$ & 0.48 & 22.90 & 0.10 & 40.38 & 36.19 \\
Diorite & 0.17 & $2,635.45$ & 1.10 & 44.26 & 0.30 & 38.66 & 32.89 \\
BXF & 0.29 & $3,116.06$ & 0.95 & 53.42 & 0.31 & 64.88 & 51.12 \\
HW Fault & 0.36 & $3,413.86$ & 1.39 & 155.66 & 1.20 & 102.15 & 86.72 \\
\hline
\end{tabular}

After the marker elements were identified from the exploration dataset, the production sample database was queried for these elements. This database consisted of over 78,000 muck samples taken from drawpoints. Production sample assay methods included an aqua regia digest with an inductively coupled plasma finish, and from these results, anomalous $\mathrm{Cr}-\mathrm{Ni}$ were flagged and plotted along with $\mathrm{Au}-\mathrm{Cu}-\mathrm{Hg}-\mathrm{As}$ values (Figure 4). These plots clearly showed an increase in gold and copper values, immediately before an increase in picrite dilution. The elevated Au and Cu values also corresponded with an increase in $\mathrm{Hg}$-As values, which indicated high grades associated with fault material that, given the geological model, were known to be formed along the picrite contact to the south.

The plots generated from the production sample database were comprehensive in time, as sampling of drawpoints began immediately after production began. This ensured that an accurate representation of the marker element dispersal across the footprint was captured from the beginning of mine life.
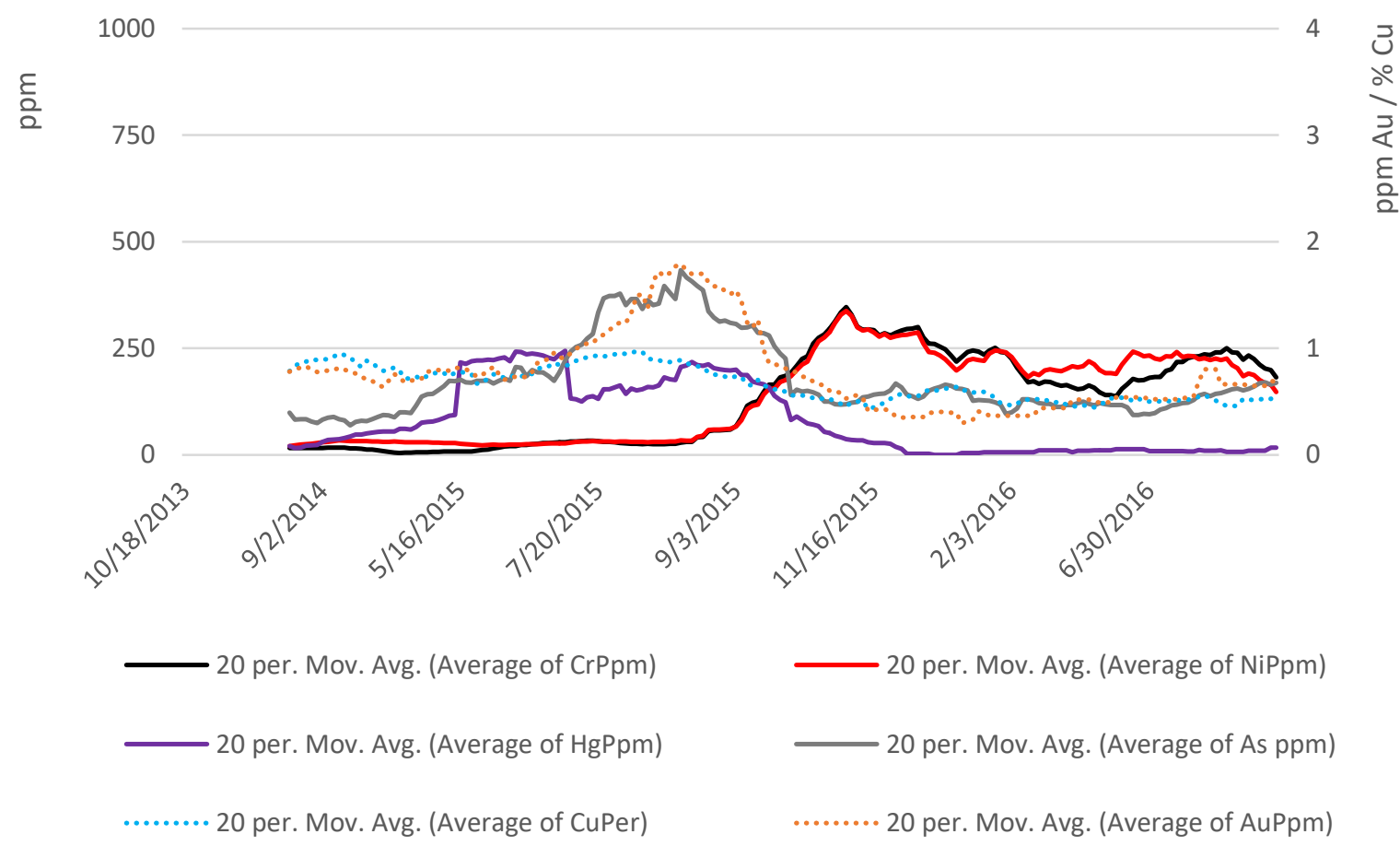

Figure 4 Geochemistry plot of marker elements by drawpoint

\subsection{Picrite dilution}

The geochemistry plots for each drawpoint give an indication to the timing and extent of external picrite dilution, in both the West and East Caves. Many drawpoints produced minor amounts of picrite throughout their lifetime, while others produced more than expected, when taking into consideration their location relative to both the HW Fault and the picrite to the south. 


\subsubsection{West Cave picrite dilution}

Minor picrite dilution along the southernmost strike drive was noted towards the end of the drawbell lives. Generally, the elevated $\mathrm{Ni}-\mathrm{Cr}$ values followed increased $\mathrm{As}-\mathrm{Hg}$ values, indicating the presence of fault material prior to the picrite infiltration. Early depletion was observed in the southern drawpoints of the West Cave. However, it was primarily due to monzonite dilution. The transition from low-grade monzonite to a monzonite/picrite blend within the southern drawpoints was not surprising, given that the picrite overhangs the monzonite intrusion along the HW Fault contact to the south.

\subsubsection{East Cave picrite dilution}

Picrite dilution throughout the East Cave was much more complex than that observed in the West Cave. Visual drawpoint inspections initially noted increased amounts of picrite in the central East Cave, which was unexpected at the time due to the height of draw and proximity to the HW Fault.

Upon further examination, it was determined that picrite infiltration was correlating well with increased As-Hg values. Though these elevated values cannot be solely attributed to the HW Fault, as other faults within the deposit exhibit similar As-Hg signatures. It became clear that picrite from the south was being introduced through structures cross-cutting the footprint. Prior to the increased $\mathrm{Ni}-\mathrm{Cr}$ values which indicated the presence of picrite, elevated Au-Cu values were observed in many of the drawpoints, and these along with the heightened As-Hg values, gave stronger evidence to the theory of picrite following structure.

An important observation with respect to the tracking of the picrite throughout the drawpoints in the East Cave is the fact that very few drawpoints maintained elevated picrite levels for a sustained period of time, but rather tapered after reaching peak values. This was interpreted to mean that picrite inflow into the cave was a temporary event which may have deposited a layer of picrite dilution across parts of the cave. The timings of the picrite spikes and recessions would be used to help model the picrite event and flow behaviours in the East Cave.

\section{West Cave modelling}

Following the early depletion of southern bells in the West Cave in 2014, New Afton engaged Dassault Systèmes Canada Software Inc. to consider the PCBC model parameters and to compare the results using inclined draw cones as opposed to vertical draw cones in an effort to improve grade reconciliation and reserve estimation in the West Cave. A PCBC model for the West Cave was created based on surface subsidence observations and drawpoint grade data. Model iterations were tested against copper and gold assays for improved reconciliations in both individual drawpoints and whole strikedrives.

\subsection{West cave calibration}

To begin calibration, the subsidence contours were imported into PCBC (Figure 5), and an approximate orientation between the footprint and centre of subsidence was determined. Parameters that would affect the volume and timing of picrite dilution in the model were tested for effect. Various tilts for all draw cones between 80 and $90^{\circ}$ were tested, and other inputs such as mixing horizon, rill angle, horizontal mixing rates, erosion rates, variable strikedrive tilts and alternative mixing methods such as template mixing were tested in various combinations. 


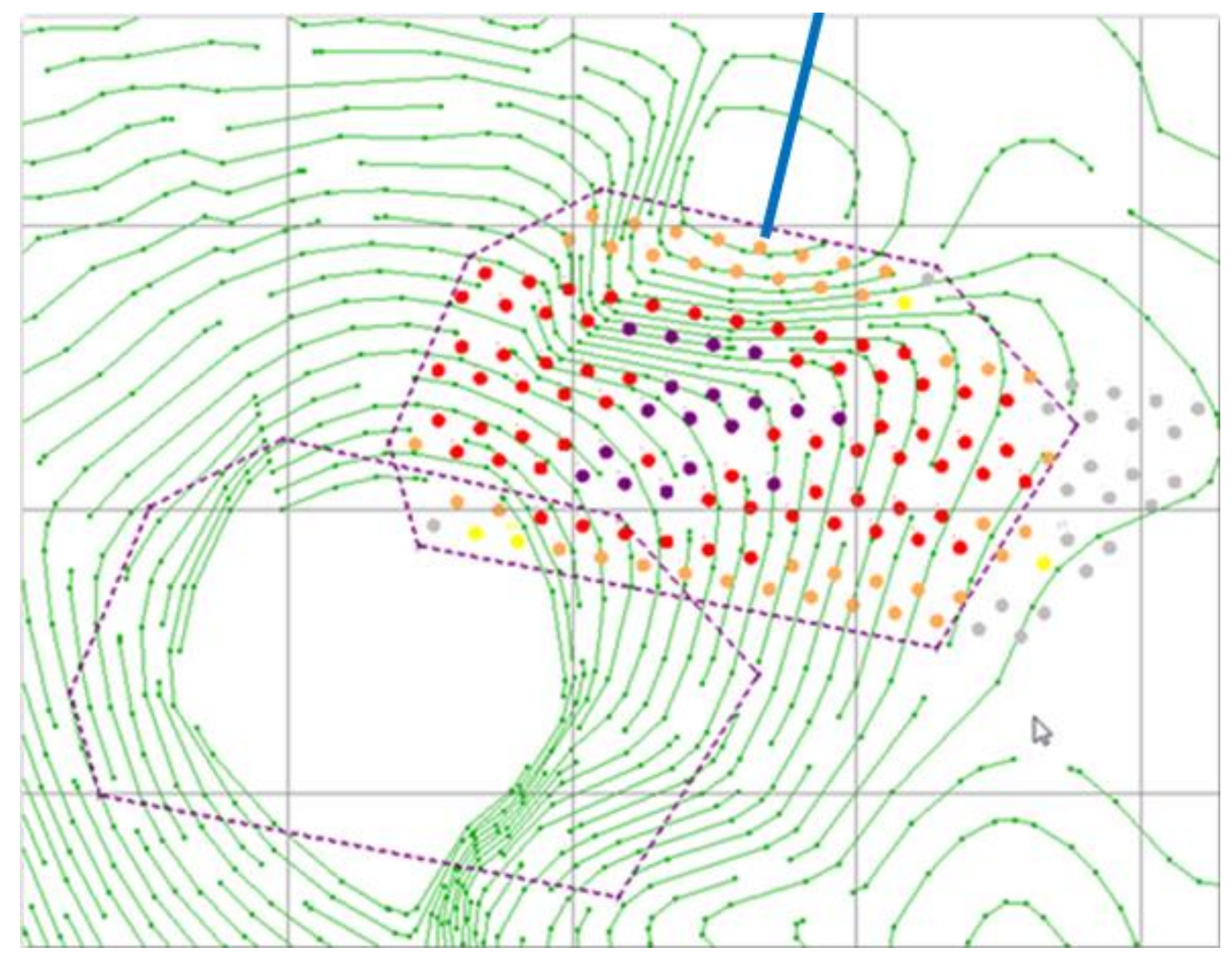

Figure 5 West Cave drawpoint locations compared to surface subsidence contours and cave probe hole drilled from the north (blue)

A probe hole drilled from the north of the cave in early 2015 indicated that the cave was growing vertically on the northern side. This supported the hypothesis that the tilt of the cave was not consistent throughout, and that a variable tilt between strikedrives would be most accurate. Probe hole location is shown in blue in Figure 5.

After a series of iterations, a best fit model was ultimately determined using variable drawcone tilts. The southern draw cones were tilted at $78^{\circ}$ southwest, which corresponded to the offset of surface expression of subsidence. Each subsequent drawpoint line was tilted $2^{\circ}$ closer to vertical in a fan-like pattern. Drawpoints were tilted towards the south at a $225^{\circ}$ azimuth to match the surface expression of subsidence. This tilt direction was also supported by the poor column height and grade reconciliations along the southern boundary.

Although these drawpoint orientations provided improved reconciliation in the majority of the West Cave, there was an outlier group of six drawpoints in the northwest edge of the cave. It was hypothesised that a localised fault cutting through these drawpoints was directing their growth to the northwest. These drawpoints were adjusted to an orientation matching the localised fault, and greatly improved reconciliation was observed. The finalised tilt angles for each West Cave drawbell can be seen in Figure 6. The outlier group is shown circled in red. These draw cones were given an azimuth of $355^{\circ}$. All other draw cones were kept at the $225^{\circ}$ azimuth matching the subsidence. 


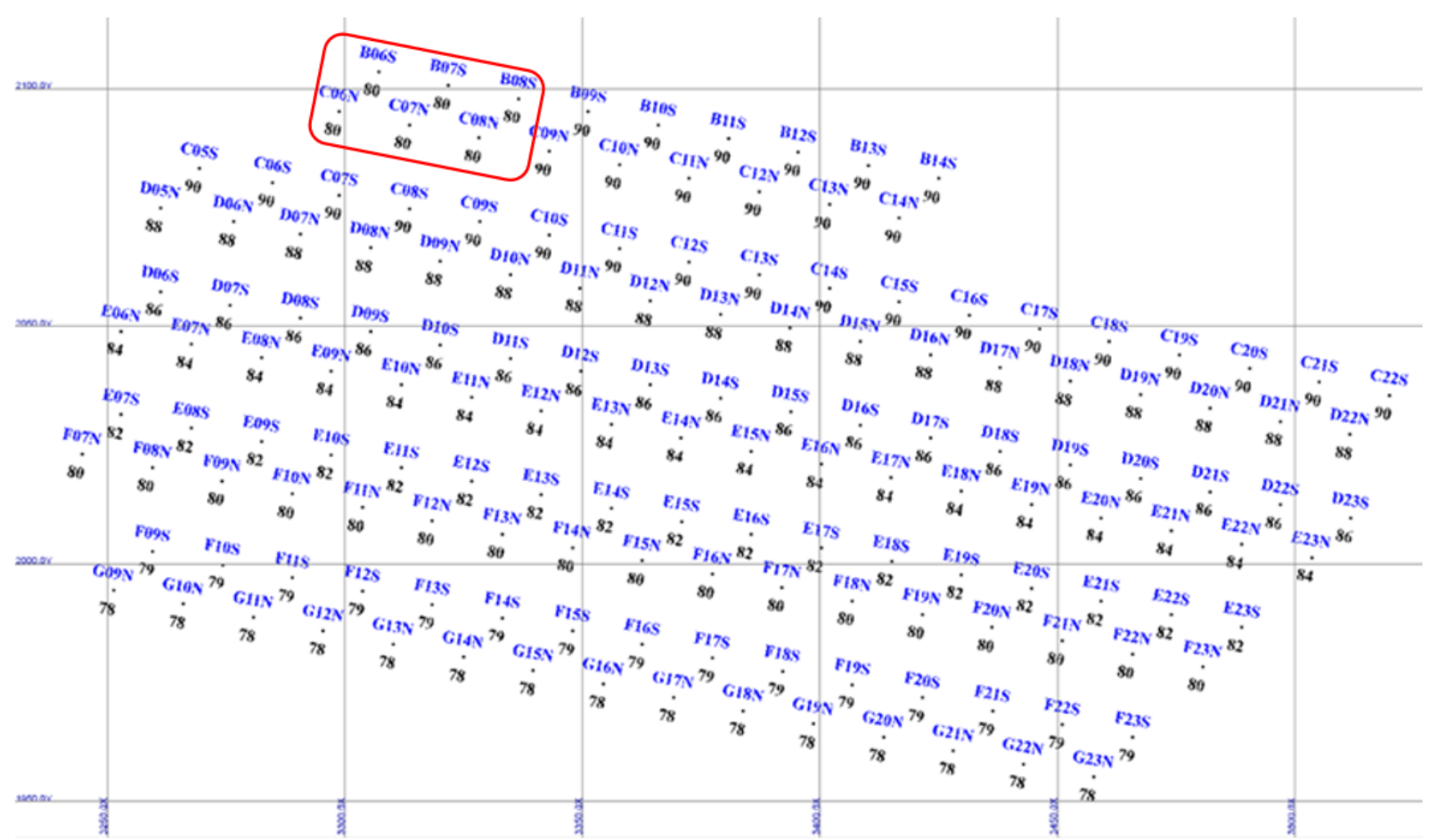

Figure 6 Finalised West Cave drawpoint dip angles. Outlier group circled in red

Due to the tilting of the draw cones in the new fan pattern, there was less overlap and interaction between strike drives at the maximum extents of the draw cone. To remedy this, the maximum radius of the cone size in the West Cave was increased from a 12 to $16 \mathrm{~m}$ radius. This was necessary in order to maintain interaction, and avoid leaving unrealistically high columns of sterilised material in the PCBC model between draw cones. The tilted cave model is visualised in Figure 7.

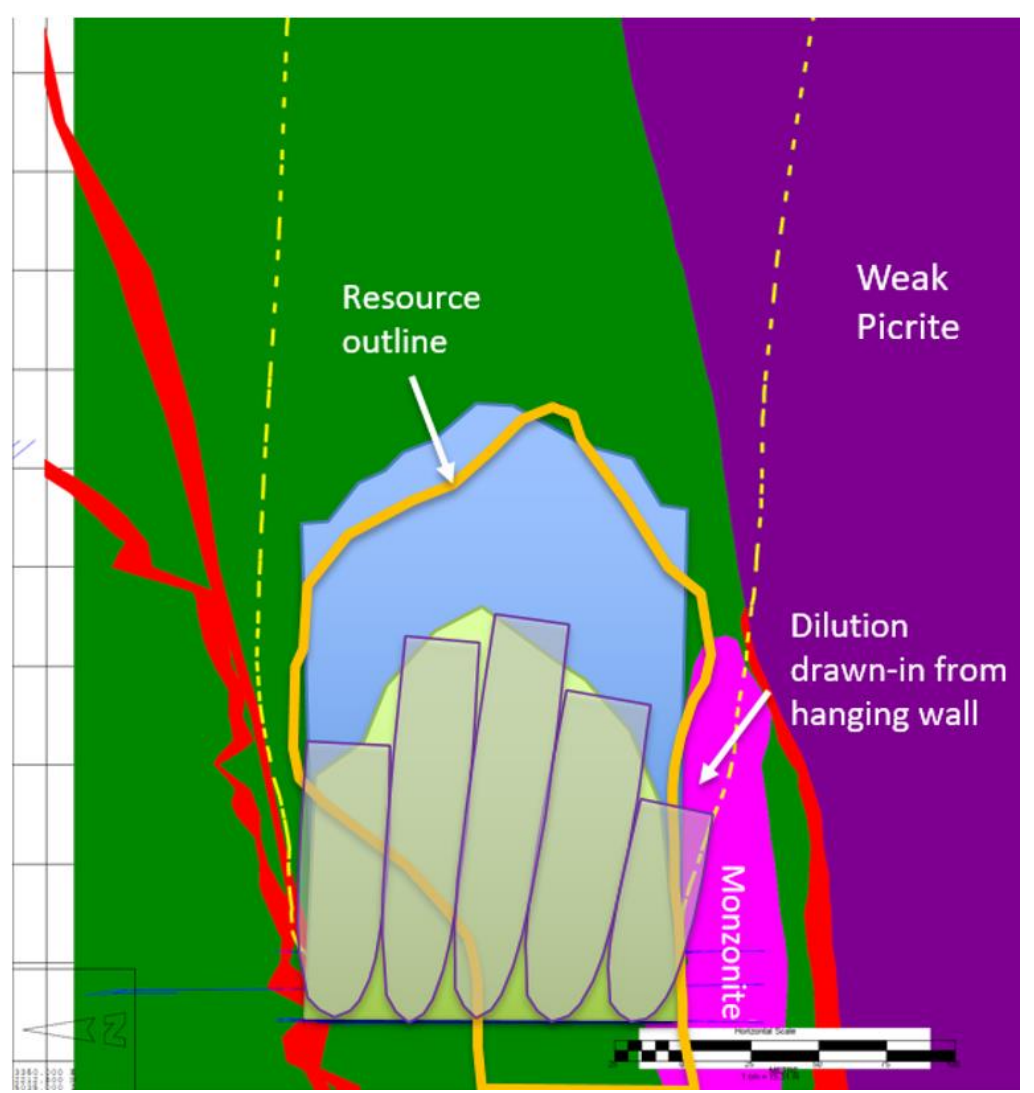

Figure 7 Visualisation of tilted and fanned West Cave draw cone model 
In order to more accurately model the complex material movement proposed within the inclined draw cones, the mixing method used in $\mathrm{PCBC}$ was changed from pre-vertical mixing to template mixing. In pre-vertical mixing, material in the PCBC slice file (which is akin to a block model within PCBC) is mixed vertically within draw columns according to input parameters. This mixing occurs in advance of any drawpoint depletion, as interaction between adjacent draw cones is irrelevant. By contrast, the template mixing algorithm allows for both vertical and horizontal mixing to occur, as well as rilling and toppling between adjacent draw cones. Due to the dependency on adjacent draw cones and previous movement of material, the mixing within the slice file occurs during each step of the PCBC schedule. This allows for more realistic mixing outcomes in non-vertical cave growth situations. The result of the template mixing model and increased cone sizes was higher dilution as drawpoints mature, resulting in increased tonnes at lower grades versus the original vertical mixing model.

\subsection{West Cave reconciliation results}

The tilted draw cone model improved overall grade estimates in the West Cave. Although the old vertical model showed good copper grade correlation with the assay data up until Q4 2015, it began to diverge significantly after that point, assumed due to the result of the increased picrate dilution being seen in the drawpoints, which was not accounted for in the original model. At this point, the PCBC model was estimating grades much higher than what was being assayed at the drawpoints. The dilution in new tilted model reduced grade estimates and increased total tonnage estimates, which correlated better with the actual performance data moving forwards than the original vertical model.

\section{$4 \quad$ East Cave modelling}

In late 2015, increasing picrite dilution continued to be observed in the East Cave drawpoints, and grade reconciliations began to deviate significantly from the PCBC model. In early 2016, efforts to develop a new calibrated dilution model for the East Cave began, which would attempt to utilise the geochemical picrite dilution data as guidance. New Afton once again engaged Dassault Systèmes Canada Software Inc. to consider the PCBC model parameters being used, and test some non-vertical cave growth scenarios for the East Cave. The initial hypothesis used when beginning the calibration effort was that the non-vertical cave growth in the East Cave was similar to that of the West Cave.

\subsection{East Cave tilted draw cone model}

Based on the picrite dilution seen in the footprint, it was initially assumed that the cave was growing preferentially towards the weak picrite rock to the south. Initial modelling attempts included broad tilting of the draw cones towards the subsidence zone and picrite, similar to what had produced good results in the West Cave. However, the picrite trends observed in the geochemical analysis could not be reproduced by modelling the draw using tilted cones. The drawpoints in this model continued to see increasing picrite infiltration until they became uneconomical, whereas in the geochemical analysis it was observed that the levels of picrite would actually reduce after some time.

An alternative scenario was also tested in which the East Cave grew preferentially towards the West Cave through the central pillar. This model reconciled relatively well to the drawpoint sample data, but did not account for the picrite dilution. Varieties of different tilted models were tested ranging from a full southern lean, to a full western lean and varying dip angles, but none yielded both logical picrite dilution and improved grade reconciliations. It became clear that the tilted draw cone modelling technique was not applicable to the East Cave, and that the interactions taking place were more complex than those in the West Cave. 


\subsection{Cave back dilution model}

It was next hypothesised that the picrite was entering the cave via only the southernmost drawpoint columns, and then rilling north across the footprint. This scenario would logically explain the rate, quantity and timing of the picrite observed in the drawpoints. In order for this sort of rilling to occur, it likely meant the cave's growth was stunted in the north, and the cave was growing disproportionally in the south; most likely due to draw control practices and uneven draw. It was also determined that in order for the observed volume of picrite dilution to be possible, there was likely a 'rat-hole' present on the southern edge of the cave which was growing preferentially into the weaker picrite.

The dilution model developed to recreate this hypothesis was based on consultant recommendation to use phantom drawpoints to mobilise picrite in the model and set cave backs in PCBC to limit/direct cave growth, and force rilling. The premise of the model is illustrated in Figure 8. Other PCBC inputs that were adjusted included changing the mixing horizon from 75 to $120 \mathrm{~m}$, internal template mixing rilling angle set to $30^{\circ}$, and fines percentages in picrite increased to $90 \%$.

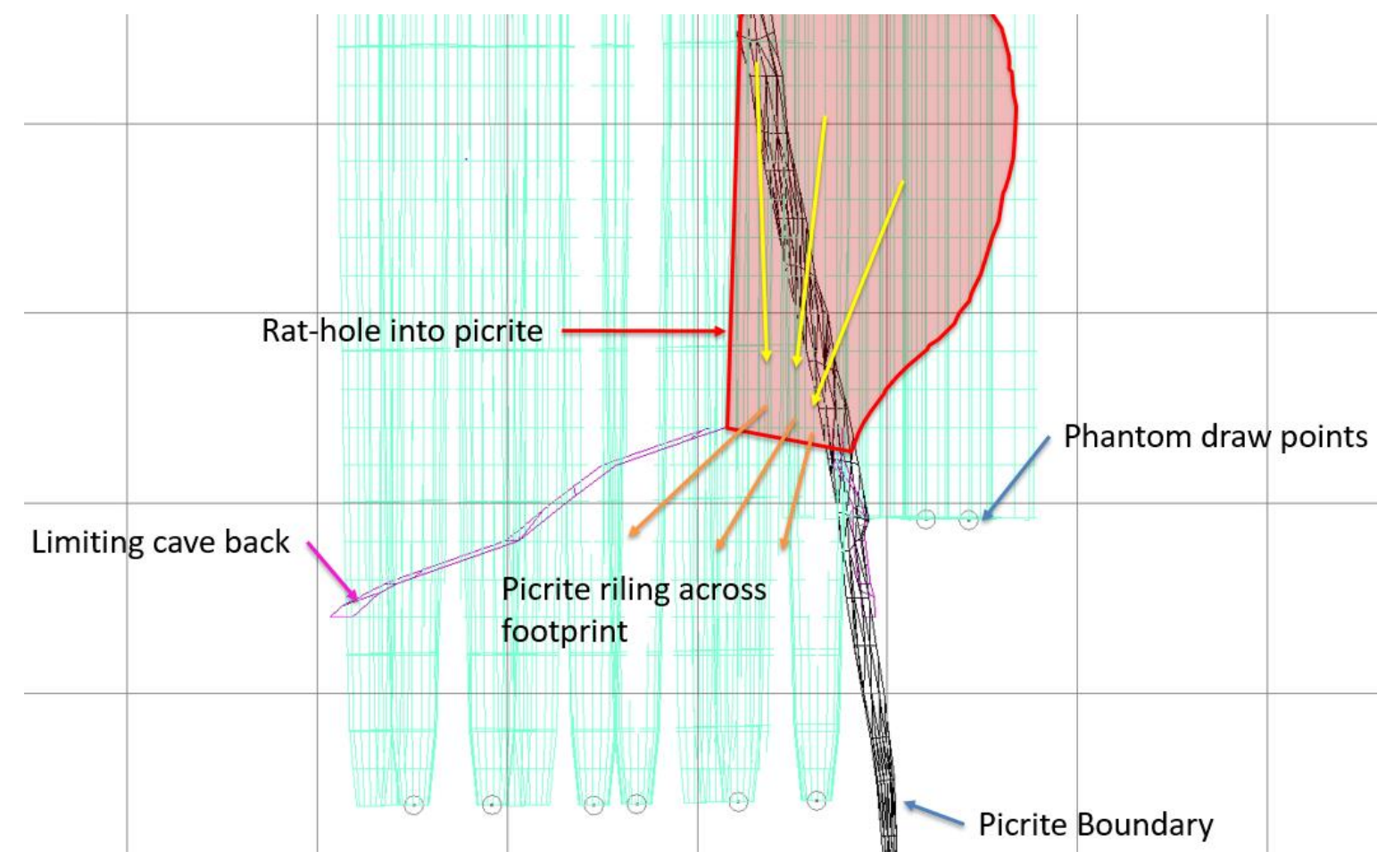

Figure 8 Diagram of the hypothesised picrite dilution interaction

Firstly, the unique rock properties of the picrite material were built into the block model, allowing the picrite to be tracked and reconciled in the production schedules. Picrite is a weaker material than the other host rocks and has a different fines parameter. A new rock code was created for the picrite material and assigned $90 \%$ fines to increased flow.

Phantom drawpoints are drawpoints created around the footprint boundary within PCBC, used to activate more background material into the slice file and template mixing. They are never opened or drawn from in the PCBC schedule. The phantom drawpoints were laid out across the southern edge of the East Cave, and up through the central cave (Figure 9). They are placed at an elevation $75 \mathrm{~m}$ above the production level, and their spacing matches that of adjacent drawpoints on the footprint. Phantom drawpoints were given a cone size of $16 \mathrm{~m}$ radius at all heights to ensure they have sufficient overlap for horizontal mixing and rilling. 


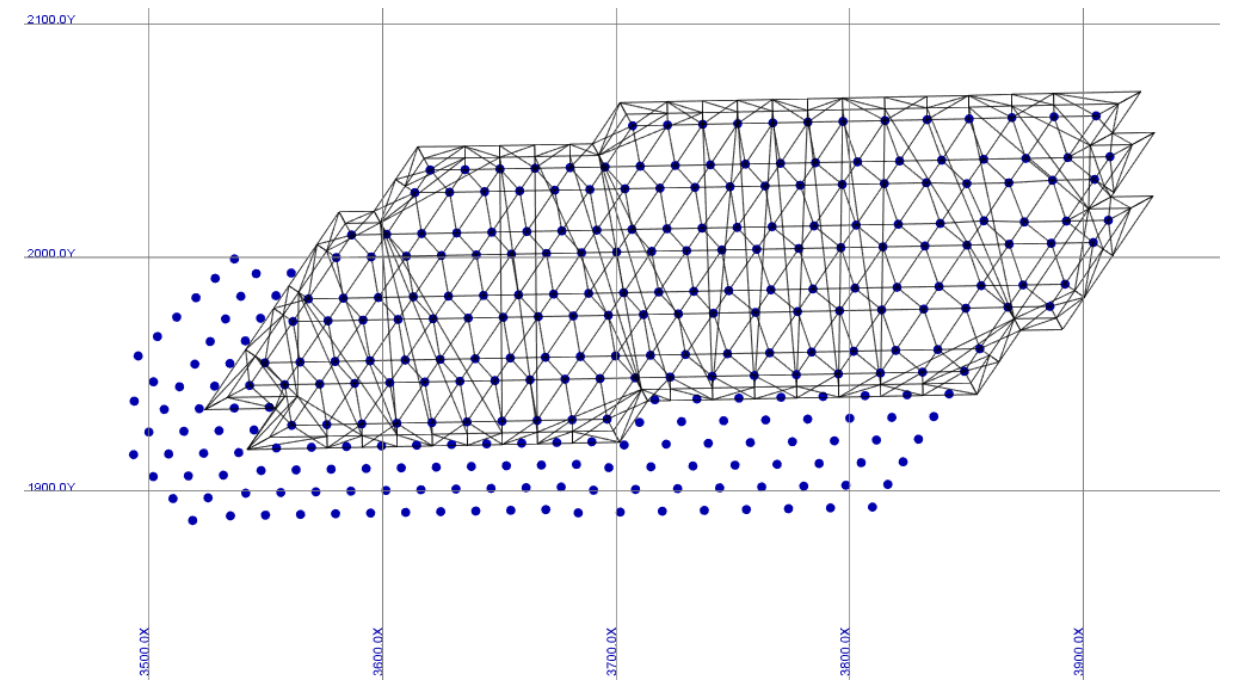

Figure 9 Phantom drawpoints outside the southern edge of the East Cave (black wire frame)

Cave shape interpretations can be used in PCBC to limit or direct cave growth in cases where it is assumed that the cave is not growing in a consistent manner. Setting a cave back limit in PCBC is done on a drawpoint-by-drawpoint basis, and sets a vertical limit from which that drawpoint can take new material from its column in the slice file. Once a drawpoint hits its set cave back limit, it will be forced to take material from adjacent columns, thus forcing rilling. Cave backs can be applied, changed and removed by period in the PCBC schedule.

An initial cave back was first 3D modelled in Vulcan and then transferred into PCBC as a triangulation (Figure 10). For PCBC to use the cave shape information, it must be converted into a bucket. The cave back bucket stores the height of the cave back triangulation above each drawpoint. PCBC can then use this height value to limit the draw cones' growth while that cave back bucket is applied. A cave back bucket value of zero for a drawpoint sets no restriction to the cave back. This is used for the drawpoints in the rat-hole.

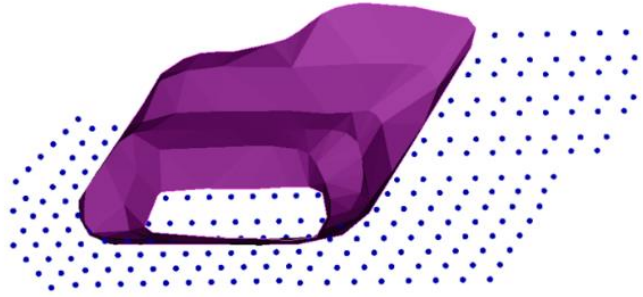

(a)

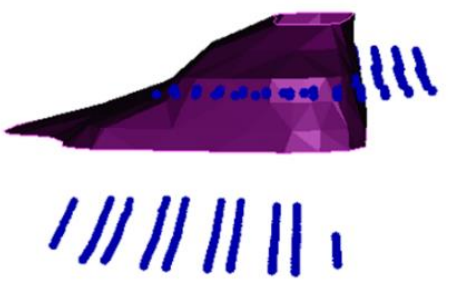

(b)

Figure 10 (a) Plan view of the estimated cave shape; and, (b) View looking east of the estimated cave shape

A number of different factors were considered in the creation of cave shapes, including local geology, structures, major faults, picrite distribution, geochemical analysis, cave draw history, and undercut blasting information. The main characteristics of the cave shapes which were iterated on were the size and location of the rat-hole, and the starting height, maximum extents and slope of the cave back. All these characteristics differently affected the quantity, rate and location of picrite entering the footprint, and were iterated until correlations were made with the actual picrite and grade assay data. This model used four separate cave backs, which were raised and slightly altered over varying time intervals to manipulate the picrite flow based to find correlation with the geochemistry results.

Draw cones located within the rat-hole are left unlimited by the cave back, and serve as the entry point for picrite. The longer a cave back stays applied in the PCBC schedule, the more picrite will be pulled through the rat-hole as other drawpoints run out of their own available material. If a single cave back is left applied too long, and too much picrite is introduced to the model, it will dilute the drawpoints past the economical limit. 
Even small changes to these characteristics caused significant changes to the amount of picrite seen in the production model, so significant refinement was required to correlate the picrite in the PCBC model with the geochemical analysis. This was made more difficult by the lack of physical cave back monitoring data available in this area.

\subsection{East Cave reconciliation results}

Using the assayed copper grades and the picrite trends as guidance, the cave shapes and application timings were refined until an improved reconciliation was achieved. The finalised cave back model was built using five cave backs applied at different points over the schedule. As seen in Figure 11, the new model improved copper reconciliations significantly compared to the base model.

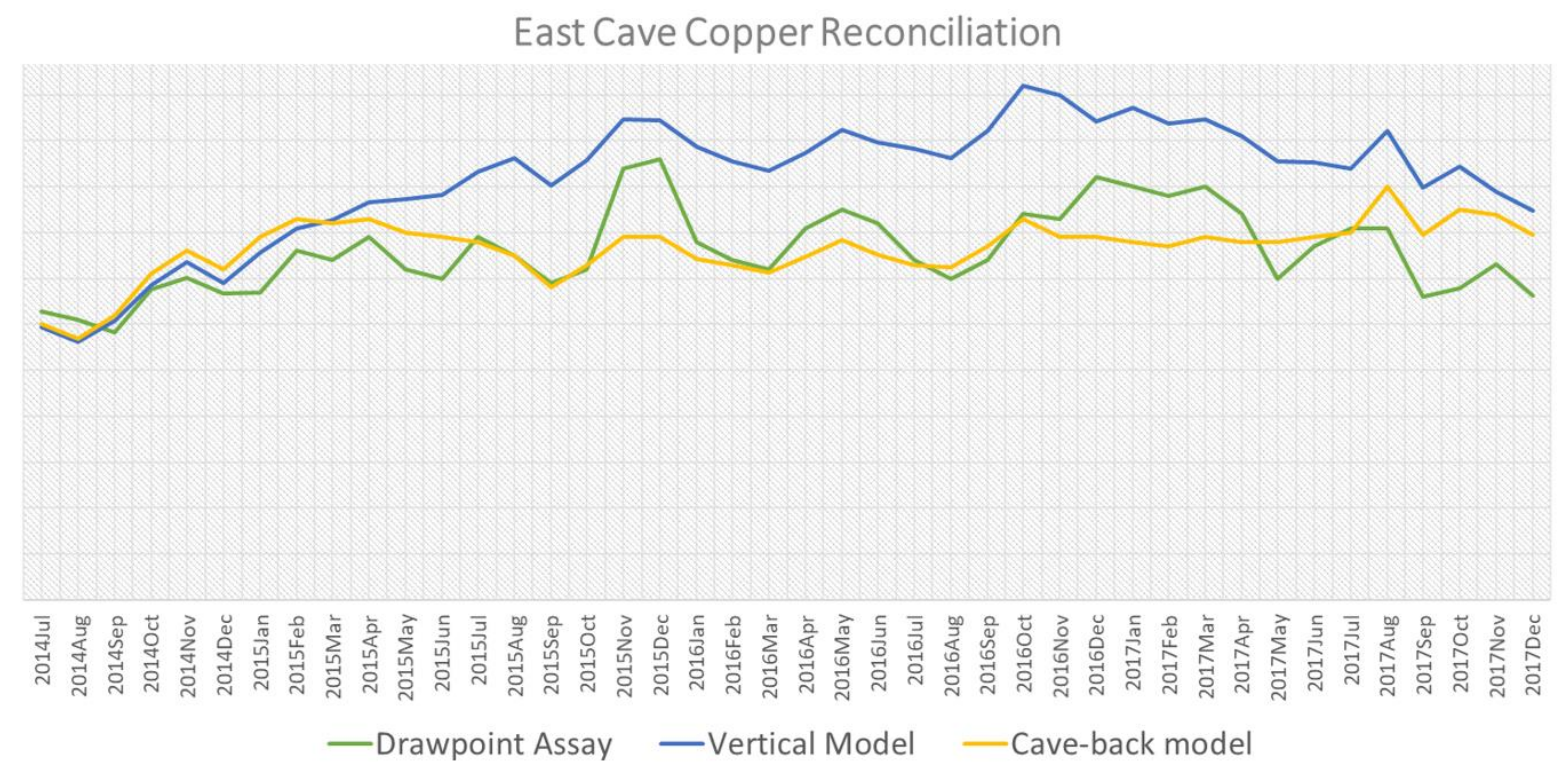

Figure 11 East Cave copper reconciliation

Due to the reconciliatory nature of the cave back model, the model needs to be reassessed frequently to determine if additional cave back adjustments are required. To date, no additional cave backs have needed to be added to the model as it has continued to track well against assays. Furthermore, improvements to draw control directed by the learnings from the dilution modelling process have led to the continued reduction of picrite reporting to the production level, indicating that the East Cave has returned to mostly vertical cave growth.

\section{Conclusion}

A considerable amount of insight into New Afton's caving mechanics was gained through the dilution data collection and cave modelling process at New Afton.

The tilted draw cone model was useful in aligning the caves growth with the observed surface subsidence impacts, and geological features.

The cave back model enabled detailed modelling of uneven cave growth and external dilution, and allowed more complex caving mechanics to be accounted for.

Detailed geochemical analysis of the external dilution proved vital to calibration process, especially in lieu of physical cave back data.

\section{References}

Lipske, J \& Wade, D 2014, Geological Model of the New Afton Copper and Gold Deposit, British Columbia, internal report to New Gold Inc. 